\title{
Francisco Tapia y Javiera Campos (Desclasificación Popular) sobre los archivos de la Comisión Valech I: «La desclasificación debe ser total ya que en la lectura total está el verdadero secreto»
}

\author{
Rita LAges y Camila PARdo
}

Universidad de Chile

Transcurridos seis años de la conclusión del informe de la Comisión Nacional de Prisión Política y Tortura, también conocida como «Comisión Valech I», creada por el Decreto Supremo 1.040 de 2003 con el propósito de identificar a las víctimas de privación de libertad y tortura por razones políticas durante la dictadura chilena y proponer medidas de reparación, el carácter de secreto de la información y documentación recogida y sistematizada por la Comisión sigue siendo cuestionado y objeto de recursos judiciales.

Hasta agosto de 2016, la Corte de Apelaciones de Santiago ha acogido catorce recursos de protección en favor expresos políticos, al amparo de la excepción del artículo 15 de la Ley 19.992, y ha ordenado al Instituto de Derechos Humanos (INDH), como organismo depositario y custodio de dicha información y documentación, dar acceso a los antecedentes solicitados por los recurrentes, en su calidad de víctimas y titulares de «los documentos, informes declaraciones y testimonios incluidos en ellos».

Para las víctimas y sus familiares, la desclasificación de los archivos de la Comisión Valech I se revela como condición esencial para conocer la verdad de los hechos ocurridos durante la dictadura cívico-militar chilena y, con ello, apurar las responsabilidades y ejercer su derecho a una reparación por la vía judicial. Para la sociedad en su conjunto, y tal como lo señaló la Corte Interamericana de Derechos Humanos, «el derecho a la verdad tiene un carácter colectivo, que conlleva el derecho de la sociedad a 'tener acceso a información esencial para el desarrollo de los sistemas democráticos’ $»^{1}$.

1. Corte Interamericana de Derechos Humanos, caso Bámaca Velásquez vs. Guatemala. Fondo. Sentencia del 25 de noviembre de 2000, párr. 197. 
En esta edición 2017 del Anuario de Derechos Humanos hemos entrevistado a Francisco Tapia, alias Francisco Papas Fritas, artista visual y activista, y Javiera Campos, magíster cientista política de la Ponticica Universidad Católica de Chle. Ambos son fundadores e integrantes de Desclasificación Popular, colectivo que ha hecho de la desclasificación de los archivos de la Comisión Valech I su lucha. Entre las acciones más emblemáticas de la agrupación, se destacan, a título de ejemplo, el Manual para desclasificar - una guía de instrucciones de cómo solicitar al INDH la desclasificación del archivos² -, o la Exposición 2054, así nombrada por ser el año en que terminará el secreto legal de cincuenta años y compuesta por cuadros, fotografías y otros materiales que documentan la información contenida en los archivos de la Comisión Valech I. En la actualidad están construyendo un archivo de acceso público, con miras a terminar con el secreto de cincuenta años y contribuir a la reconstrucción de la historia detrás de la tortura y la prisión política durante la dictadura cívico-militar.

El establecimiento del carácter de secreto durante 50 años de los documentos, testimonios y antecedentes aportados por las víctimas a la Comisión Valech I sigue siendo un tema controvertido. En su opinión, ¿cuáles son los fundamentos para su existencia y vigencia hasta el presente?

Francisco Tapia [FT]: Crear una bio-impunidad. Con esto me refiero a que las políticas públicas esperan que los cuerpos implicados perezcan y, con ellos, su memoria. Abrir la información posterior a ello es de una violencia similar a un asesinato, donde el Estado no se ensucia las manos y mantiene la impunidad de los implicados en violaciones de derechos humanos, pasando a ser un anecdotario.

En su opinión, ¿qué especificidades tiene el secreto de la Comisión Valech I respecto de lo establecido por las otras comisiones de verdad que se han constituido en Chile?

Javiera Campos [JC]: Si comparas la legislación de las comisiones Rettig, Valech I y Valech II, se puede ver que solo para la comisión Valech I se establece el secreto en una ley. Y, en esa misma ley, se regula la reparación. Nos llama la atención que se haya puesto este secreto en una ley de reparación, porque no fue establecido en el decreto que crea la comisión. Las demás comisiones sólo tienen reserva. Por ejemplo, en [la comisión] Rettig: el decreto que la crea establece la reserva y la obligación de pasar los archivos a los tribunales; en la ley de Comisión Valech II también hay reserva y asimismo en la ley que crea el INDH.

El levantamiento del secreto es la principal causa del colectivo Desclasificación Popular. ¿Cuáles son los motivos y los objetivos de su reivindicación?

2. El manual se encuentra disponible en http://bit.ly/2vGBLvN. 
FT: Construir memoria y sobre todo una memoria rebelde hacia la dictadura, de la rebeldía de quienes cayeron en manos de la violencia y resistieron ante ello. No una memoria cargada de tristeza, sino de orgullo de lucha. Y para ello creo que debe existir una participación de las expresas y expresos políticos en escribir esta historia sin esperar que el Estado cree un hito de desclasificación. Ahora, en términos técnicos, creemos que el hecho de que más personas usen esta vía de desclasificación nos permite cruzar la mayor cantidad de información y abrir esa información para que otras personas u orgánicas desarrollen investigación. Y que no sea solo para un uso institucional y reservado.

El secreto que establece la ley no es absoluto, ya que existe la excepción contemplada en el artículo 15 que se configura con el derecho de los titulares para acceder a los antecedentes. ¿Por qué es importante que exista una desclasificación total de los archivos?

FT: Bueno, ese derecho personal no se conocía hasta que nosotros nos preocupamos de ello y hemos dado difusión a este derecho. Aparte de ganar este derecho contra el INDH que no lo aceptaba y realizaba otra lectura de esta ley. Ahora, para mí en especial retirar [los antecedentes] y el gesto de hacerlo público es un acto de desobediencia civil, que no acepta los cincuenta años de secreto, ni una revelación sectorial de la información para jueces y fiscales. Este acto se realiza entendiendo que los documentos por sí solos no tienen el mismo peso que tienen al construirse una base de datos que haga cruces de información entre un archivo y otro. Por eso, la desclasificación debe ser total ya que en la lectura total está el verdadero secreto.

JC: Hemos trabajado sobre la base de que nadie le ha preguntado a los expresos y expresas si querían que esta información se hubiera establecido como secreta. Nosotros consideramos que es válido que las personas quieran hacer pública esta información. Por lo tanto, esa es la primera reivindicación: lograr que las personas dueñas de esos archivos los recuperen. Incluso, si hay gente que no los quiera en sus manos, dado el fuerte trauma que sufrió y que no quiere revivir, es su decisión no recuperarlos.

Consideramos que es muy importante que los tribunales tengan acceso a esos archivos. De octubre de 2015 hasta febrero de 2017, hemos desclasificado 63 archivos de las comisiones Valech I y II, no calificados como víctimas. Nos hemos dado cuenta de que en la sola lectura es posible recabar mucha información: se ahorrarían años de investigación en los procesos judiciales. Si un juez o ministro en visita tuviera en sus manos estos documentos, que son acreditados por una institución del Estado, podría dar por acreditados los hechos. (...) Hemos identificado que hay una base de datos informática, en la que uno podría ingresar un centro de detención y saldría una lista de todas las personas que estuvieron detenidas en tal recinto, tanto de Valech I como de Valech II. 
Haydée Oberreuter, exprisionera política y dirigenta de derechos humanos, solicitó el acceso a dicha base de datos, esta solicitud fue rechazada por el Consejo para la Transparencia y por el INDH. Ante esta decisión se interpuso un recurso por ilegalidad presentado ante la Corte de Apelaciones de Santiago. El 3 de mayo tuvieron lugar los alegatos, y en unos días más, la Corte de Apelaciones de Santiago deberá decidir si denegar esta base de datos es un acto legal o no. Esta herramienta es crucial para que la justicia sepa en detalle sobre los crímenes de lesa humanidad y torturas realizados en la dictadura cívico-militar. También ayudaría a esclarecer los casos de detenidos desaparecidos y ejecutados políticos.

Hay muchas historias que no hemos abordado porque este secreto lo han acallado. Entonces es también un aprendizaje de nuestra historia política más allá de la historia oficial, la que se enfoca [principalmente] en la tortura física. Como hemos dicho en otras instancias, en Desclasificación Popular queremos hacer la historia de la resistencia a la dictadura cívico-militar.

Ante este derecho que reconoce la ley y que podría entenderse de su interpretación literal, ¿cuáles han sido las razones del INDH para negarse a entregar los antecedentes que se solicitan? ¿Cómo se explican esa negativa ante una ley que parece tan clara?

JC: Hubo dos etapas con el INDH: entre octubre y noviembre de 2015 nosotros hicimos la primera solicitud a través de una carta formal con doce expresos. Ellos se reunieron con Lorena Fríes y ella les dijo que el artículo del secreto no se ha derogado y debe cumplirlo. Por lo tanto, lo que se entregaría serían los documentos que cada expreso entregó a la comisión. El trabajo de la comisión no se entregaría porque no se podía hacer más con este artículo.

En el momento en que presentamos los recursos de protección, hubo un cambio en la dirección del INDH y asume Branislav Marelic, con quien nos reunimos y nos señaló que se establecería un nuevo criterio para entregar la información solicitada. Tal criterio sería que, si se solicitan los antecedentes, el INDH revisaría previamente los antecedentes y se tacharían a terceros víctimas, pero no de los terceros victimarios. Otro de los criterios establecidos es que, si se apela de ese tachado, el INDH también alegaría y llegarían hasta las últimas consecuencias para proteger esos datos sensibles. Ese es el criterio que rige hoy. Estamos estudiando la pertinencia y conveniencia de ese criterio.

Antes de la interposición de los recursos de protección, ¿quiénes y qué otras vías se ejercieron para exigir que el INDH entregara los antecedentes?

JC: Las campañas anteriores al trabajo de Desclasificación Popular apelaban a cambiar los cinquenta años de secreto por ley. Por lo tanto, tenía que haber un proyecto de ley. En 2015, antes de los recursos de protección, teníamos la idea de la carta 
formal, pero no había respuesta positiva por parte del INDH, o entregaban solamente los documentos que aportó el expreso. $Y$ en los casos que negaban los antecedentes, no hubo respuesta negativa expresada en algún documento. Ante esta situación, los abogados [Paz Becerra y Álvaro Aburto] idearon solicitar la información por la Ley de Acceso a la Información Pública. Ellos asesoraron a las víctimas en la solicitud. Nosotros el 2016 hicimos lo mismo, y de esta manera obtuvimos la respuesta del INDH de manera expresa en un documento, lo que nos permitió interponer los recursos de protección posteriormente y obtener los archivos íntegros.

Es incuestionable que los fallos de la Corte de Apelaciones que han ordenado el acceso a la información y documentación solicitada por los recurrentes, en su calidad de víctimas y titulares de «los documentos, informes declaraciones y testimonios incluidos en ellos", marcan un hito importante en la jurisprudencia nacional sobre el carácter secreto de los archivos recabados por la Comisión Valech I. En su opinión, ¿cuál puede ser el real alcance de estas sentencias en cuanto a la vigencia del secreto y qué significa para la causa por la desclasificación total?

Jc: Creo que cada día es más insostenible. Todo el mundo al menos está consciente de que en tribunales ya no es tan válido. Tengo entendido que muchos expresos que tienen causas judiciales han pasado sus archivos a tribunales. Entre más expresos y expresas desclasifiquen sus archivos, con nosotros o fuera de Desclasificación Popular, va a llegar un momento en que la opinión pública exigirá que se avance en un proyecto de ley. Después del fracaso del proyecto de ley del año pasado, se presentó otro que tiene lo mínimo: corrige el artículo 15 permitiendo el acceso a los tribunales a los archivos, lo que nos acercará, modestamente, a lo que fue [la comisión] Rettig. Hoy se estan liberando los antecedentes para que el resto de los ciudadanos y el resto del mundo lean los archivos, y que los jueces y abogados empiecen a ocuparlos. Algo va a pasar, se les va a pedir la cuenta tanto a los legisladores como al gobierno. Hay académicos leyendo los archivos y trabajando a partir de esta desclasificación, tanto en Chile como en otras partes del mundo.

Nosotros tenemos un archivo: el de la última Exposición 2054, de una persona de Quinta Tilcoco que tiene el nombre de su torturador. Mucha gente le decía a esa persona que nosotros estábamos equivocados en la interpretación del artículo 15 de la Ley 19.992, y que en los archivos no había nada. En el archivo que comento se señala que el teniente Medina había torturado. Esa es una prueba.

La Corte de Apelaciones, a través de los fallos, ha ordenado al INDH entregar los antecedentes, pero nada dice en cuanto a lo que se debe entregar y cómo entregarlos, quedando el criterio a cargo del INDH. Según su experiencia, ¿qué antecedentes se están entregando y cuáles son los criterios del INDH para proceder a esa entrega? 
JC: En el dictamen de la Corte de Apelaciones, tanto el de diciembre de 2015 como el de septiembre de 2016, la entrega fue íntegra: la Corte ordenó entregar todos los antecedentes, sin tachados. Después de septiembre, el INDH adoptó el criterio de tachar los antecedentes. Nosotros creemos que esa entrega debe ser íntegra. Considero que es inconcebible que el INDH esté aplicando la Ley de Datos Personales a asuntos de derechos humanos. Tengo entendido que esa ley actualmente es bastante mala y antigua.

[Los abogados] Paz Becerra y Francisco Jara presentaron un recurso de ilegalidad por una expresa ante la negativa de entregar la base de datos. El caso que les comenté anteriormente. En su alegato dijeron que de acuerdo al artículo 20 de la Ley de Acceso a la Información Pública, si hay datos de terceros, la institución pública debe contactar a los terceros mencionados en los antecedentes. El INDH no lo está haciendo. Nosotros le hemos consultado al INDH y nos han señalado que contactar a terceros es insostenible.

En septiembre de 2016, el INDH, dando cumplimiento a las decisiones judiciales, ha entregado los antecedentes solicitados a las víctimas recurrentes. En diciembre del mismo año, mucho de ese material se ha dado a conocer al público, por primera vez, en una exhibición titulada 2054 y organizada por ustedes. ¿Qué otras iniciativas y actividades tienen pensadas?

FT: Por ahora, mi obra fue crear Desclasificación Popular, posicionarlo desde distintos flancos en conjunto con el colectivo que se fue creando, como una organización seria que seguirá desarrollando investigaciones al respecto de los archivos y el secreto. Todo este trabajo tenía contemplada una exposición que muestra el trabajo de dos años y nuestra posición política frente al Estado y sus políticas de «la medida de lo posible», y de impunidad. Mi objetivo es que se cree la ONG Desclasificación Popular, para así dar un paso al costado y dedicarme a otras investigaciones.

Jc: Ahora estamos organizando distintos conversatorios, porque nos importa llegar a personas que no necesariamente sean activistas de derechos humanos, sino personas jóvenes de distintos lados que se enteren de este proceso de desclasificación. Hay un tema recurrente en Chile, el del cerco comunicacional: a nosotros nos cuesta mucho salir en los medios de comunicación. Los conversatorios nos han ayudado a difundir. El otro plan es llegar a regiones, porque hay varios expresos en regiones que no están vinculados a organizaciones. Tenemos que encontrar una forma de llegar a ellos.

\section{¿Cuáles son las conclusiones que sacan de todo este proceso?}

FT: Es difícil sacar conclusiones de algo que está en proceso. Pero aun así puedo decir que este proyecto ha generado una forma de hacer las cosas sin esperar que el Estado les dé una solución. Es una forma alternativa, pero sobre todo desobediente que permite que el cuerpo social y popular restaure la historia y su presente. Y a mi 
parecer, ése debe ser el mecanismo que debemos tomar contra las estructuras de poder, que negocian la estabilidad económica por sobre la verdad y la justicia de una sociedad que fue acribillada, violentada y torturada.

¿Cuál es el objetivo de mediano y largo plazo de vuestra organización respecto del tratamiento de la información obtenida por las víctimas, que eventual y voluntariamente vayan ustedes recogiendo?

JC: Por el momento hay dos personas de Desclasificación que se encargan de los archivos: un historiador y una antropóloga, Luciano y Daniela. Ellos están armando el archivo y decidiendo cómo subirlo, qué datos subir. Porque, independiente de que nos pasen los archivos íntegramente, hay datos que proteger, como direcciones, teléfonos y datos personales que tachamos. Por el momento, estamos viendo la integridad del archivo y a futuro se van a implementar reglas de cómo citar el archivo, para que pueda usarse. Hay una red de archivos: nos invitaron y estamos en proceso y en conversaciones para hacer alianzas.

Frente a este acceso efectivo por parte de las víctimas a los antecedentes recabados por la Comisión Valech I, ¿cómo las organizaciones de derechos humanos pueden contribuir en el proceso de construcción de memoria colectiva?

FT: Generando una red de apoyo y confianza entre las organizaciones y con los expresos y expresas políticas, enseñándoles a desclasificar y publicar, o poniéndolos en contacto con nosotras y nosotros. También apoyando futuras campañas de difusión para que esta vía de desclasificación avance sin esperar una ley del gobierno. Creo que los gobiernos han hecho oídos sordos y han hecho una gran política de maquillaje frente a la realidad de los derechos humanos. Por eso, creo que es necesaria la unión y responder desde fuera del Estado con una herramienta que es útil para todos los que no creemos en el perdón ni en el olvido o creemos en frases como «sin memoria no hay futuro».

\section{Sobre las autoras}

Rita Lages es profesora asistente de la Facultad de Derecho de la Universidad de Chile. Actualmente es la encargada de contenidos de extensión del Centro de Derechos Humanos de la Facultad de Derecho de la Universidad de Chile. Licenciada y magíster por la Facultad de Derecho de la Universidad de Coimbra, Portugal. Diploma en Estudios Avanzados en Derecho Europeo y candidata a doctora por la Facultad de Derecho de la Universidad Complutense de Madrid.

Camila Pardo es egresada de la Facultad de Derecho de la Universidad de Chile. Ayudante ad honoren del Centro de Derechos Humanos de la Facultad de Derecho de la Universidad de Chile. 
